\title{
RNA editing in Drosophila melanogaster: New targets and functional consequences
}

\author{
MARK STAPLETON, JOSEPH W. CARLSON, and SUSAN E. CELNIKER \\ Berkeley Drosophila Genome Project, Department of Genome Biology, Life Sciences Division, Lawrence Berkeley National Laboratory, Berkeley, \\ California 94720, USA
}

\begin{abstract}
Adenosine deaminases that act on RNA [adenosine deaminase, RNA specific (ADAR)] catalyze the site-specific conversion of adenosine to inosine in primary mRNA transcripts. These re-coding events affect coding potential, splice sites, and stability of mature mRNAs. ADAR is an essential gene, and studies in mouse, Caenorhabditis elegans, and Drosophila suggest that its primary function is to modify adult behavior by altering signaling components in the nervous system. By comparing the sequence of isogenic cDNAs to genomic DNA, we have identified and experimentally verified 27 new targets of Drosophila ADAR. Our analyses led us to identify new classes of genes whose transcripts are targets of ADAR, including components of the actin cytoskeleton and genes involved in ion homeostasis and signal transduction. Our results indicate that editing in Drosophila increases the diversity of the proteome, and does so in a manner that has direct functional consequences on protein function.
\end{abstract}

Keywords: adenosine deaminase; Drosophila; RNA editing; ADAR; nervous system; transcriptome

\section{INTRODUCTION}

RNA editing is a well-established mechanism in which precursor messenger RNA transcripts are subject to recoding by the enzyme adenosine deaminase, RNA specific (ADAR) (Bass 2002). ADAR catalyzes the deamination of adenosine to inosine. Inosine mimics guanosine in its basepairing properties, and the translational machinery interprets I as G. In this way, an A-to-I conversion in the mRNA can alter the genetic information that can lead to changes in mRNA splicing and stability as well as changes in protein function. ADAR is essential in all animals examined to date, and studies in mouse, Caenorhabditis elegans, and Drosophila suggest that the function of pre-mRNA editing is to modify adult behavior by altering signaling components in the nervous system (Higuchi et al. 2000; Palladino et al. 2000; Wang et al. 2000; Tonkin et al. 2002). Considerable progress has also been made in understanding the mechanism of action of the ADAR enzyme (Cho et al. 2003; Haudenschild et al. 2004; Athanasiadis et al. 2005; Macbeth et al. 2005). The molecular details of target site specificity of

Reprint requests to: Mark Stapleton, Berkeley Drosophila Genome Project, Department of Genome Biology, Life Sciences Division, Lawrence Berkeley National Laboratory, Berkeley, CA 94720, USA; e-mail: staple@ fruitfly.org; fax: (510) 486-6798.

Article published online ahead of print. Article and publication date are at http://www.rnajournal.org/cgi/doi/10.1261/rna.254306.
RNA editing are drawn from studies of the mammalian glutamate receptor gene, GluR-B. Receptor pre-mRNA forms a double-stranded stem structure by imperfect base-pairing between an exonic sequence, where the edit(s) occur, and a noncoding intronic element called the editing site complementary sequence (ECS) (Higuchi et al. 1993). Most targets, however, are found serendipitously when isolating genes from cDNA libraries. Computational identification of ADAR substrates is difficult, and little progress has been made in designing algorithms for predicting putative target transcripts. ADAR targets in the human genome have been identified and are located predominantly in embedded Alu sequences, suggesting a role of ADAR in mRNA stability (Kim et al. 2004; Levanon et al. 2004). Editing can also introduce new splice sites (Rueter et al. 1999), and editing that occurs in $5^{\prime}$ - and $3^{\prime}$-untranslated regions (UTRs) presumably alters the stability, localization, or translatability of the target mRNA (Morse et al. 2002; Prasanth et al. 2005). Recently, Yang and coworkers described an additional role of RNA editing in the biogenesis of select miRNAs involved in mammalian hematopoiesis (Yang et al. 2006).

The majority of verified targets of ADAR in Drosophila melanogaster come from a comparative genomic approach examining a distinct subset of genes consisting of ion channels, G-protein-coupled receptors (GPCRs), and proteins involved in synaptic transmission (Hoopengardner 
et al. 2003). Using this approach, conservation of the putative ECS site within neighboring introns was not an informative predictor; however, exons with the highest evolutionary conservation within a gene seemed to be the best predictive tool to identify ADAR targets for this subset of genes. The prevalence of editing sites found within the coding portions of Drosophila genes, as well as the stage-specific "self-tuning" of ADAR, could be a principal mechanism of increasing neuronal protein diversity (Keegan et al. 2005).

Although directed approaches to identify ADAR targets have been employed successfully, we have taken a different approach based on a systematic analysis of the Drosophila Gene Collection (DGC; http://www.fruitfly.org/DGC). The DGC contains cDNAs representing 10,398 of the predicted 13,449 genes in D. melanogaster

(Release 4.1). This collection originates from cDNA libraries derived from a variety of tissues and developmental stages (Rubin et al. 2000; Stapleton et al. 2002a,b). Utilizing high-quality sequence data from full-insert sequences of adult head cDNA clones, we have identified 27 new targets of ADAR, doubling the total to 55. The edited sites verified in our analysis are within coding regions and in the $3^{\prime}$ UTRs of these targets. Previous studies (Dutzler et al. 2002, 2003) on one of our targets (CG31116), a member of the $\mathrm{ClC}$ family of chloride channels, suggest a clear functional consequence of editing upon the gating properties of the ion channel. Some target genes, like the G-protein-coupled receptor bride-of-sevenless (boss) and the calcium-activated potassium channel small conductance calcium-activated potassium channel $(S K)$, have clear roles in neuronal development and signaling, while other target genes, like spir, which is an actin nucleating factor, represent components of the cytoskeleton. The largest class of ADAR targets consists of novel genes that have not yet been assigned a functional attribute in the Gene Ontology (GO) database (Ashburner et al. 2000).

Transcriptional analyses of the human genome (Kapranov et al. 2002), the Arabidopsis genome (Yamada et al. 2003), and the Drosophila genome (Stolc et al. 2004) suggest that upward of $50 \%$ of the predicted noncoding genome is expressed. In Drosophila, noncoding transcription has been well characterized and includes microRNAs (Lai et al. 2003; Lai 2005; Leaman et al. 2005), noncoding RNAs (Tupy et al. 2005), and anti-sense RNAs (Misra et al. 2002). The complexity of eukaryotic transcriptomes continues to expand, and editing of pre-mRNA transcripts adds yet another layer of intricacy.

\section{RESULTS AND DISCUSSION}

\section{Identifying putative targets of ADAR}

In order to identify putative new targets of ADAR, we took advantage of our full-insert sequenced gene collection. As part of our cDNA analysis pipeline, we aligned each highquality cDNA sequence with the genome sequence using Sim4 (Florea et al. 1998) and recorded the base-pair discrepancies (see Materials and Methods). Figure 1 represents the results of tabulating all possible substitutions from $\sim 15 \mathrm{Mb}$ of data from full-insert sequenced cDNAs. When substitutions are grouped by library and expressed as a percentage of the total, clones from the isogenic head library possess a threefold increase in the level of A-to-G transitions when compared to clones from the other two isogenic libraries. Moreover, the A > G transition frequency in the head libraries is the only type of substitution within the isogenic libraries that has a discernible frequency above background substitutions. This analysis led us to generate a list of clones with the highest likelihood of having an A-to-G substitution due to editing and reducing the possibility of strain-dependent polymorphisms. This approach identifies both authentic editing sites as well as errors introduced by the reverse transcriptase used to generate the cDNA libraries. To distinguish these events, further experimental validation of the sites is necessary and is described below.

The analysis resulted in a list of 198 putative editing targets. Most of the known edited genes in D. melanogaster are involved in rapid electrical and chemical neurotransmission (Stapleton et al. 2002a; Hoopengardner et al. 2003; 
Xia et al. 2005). This observation is, in part, due to the neurological phenotype associated with $A D A R$-null mutants coupled with the fact that genes of this type have been specifically evaluated for the presence of editing. Although our approach is not biased in this manner, we identified 11 of the known 28 targets of ADAR as putative targets and did not pursue them further. Additionally, 10 of the remaining 17 known target genes are represented in our collections, but do not possess the A-to-G transition, suggesting that since editing is $<100 \%$ efficient, we captured the unedited mRNA in our cDNA collection. The remaining seven known targets do not have a representative EST or cDNA in our gene collection. The Sim4 alignment program encounters difficulties near the edges of sequence alignments, and putative targets with these alignment artifacts were removed from the list, further collapsing the set to a total of 108 clones containing 149 potential editing sites.

We interrogated these 149 putative editing sites experimentally by performing reverse-transcription-polymerase chain reaction (RT-PCR) followed by sequencing of the amplified products. RT-PCR was performed with total RNA isolated from adult heads of the isogenic strain. Amplicons ranged in size from $\sim 300$ to 500 bp spanning the region(s) surrounding the potential editing site(s). Sequence traces from 27 of the 108 genes yielded 58 positions with either a mixed A and $\mathrm{G}$ signal $(n=$ $51)$ or a pure $G$ signal $(n=7)$, indicating the presence of edited transcripts (Fig. 2B; Supplemental Material, contact staple@fruitfly.org). We successfully amplified regions from all 108 putative targets and obtained high-quality sequencing data for all but one (CG7569). For targets whose chromatograms showed "weak" evidence of editing (predominant $\mathrm{A}$ at the putative editing site), we cloned the products from two independent RT-PCR reactions and sequenced 48 isolates per reaction. CG31116 is an example of this weak editing, where three of the four putative sites displayed almost no mixed signal. Cloning revealed these sites are edited with frequencies ranging from $4.5 \%$ to $10.4 \%$ (Supplemental Fig. S12 and table therein, contact staple@fruit-

\section{A}

Head cDNA

Larval cDNA fly.org). To rule out the unlikely possibility that the mix of A/G signals or the pure G signal seen in the RT-PCR was due to genome polymorphisms that have accumulated in the isogenic strain, we PCR-amplified and sequenced the same regions from genomic DNA isolated concomitantly with the RNA. None of the 58 sites is due to polymorphisms in the genomic DNA (Fig. 2B; Supplemental Material, contact

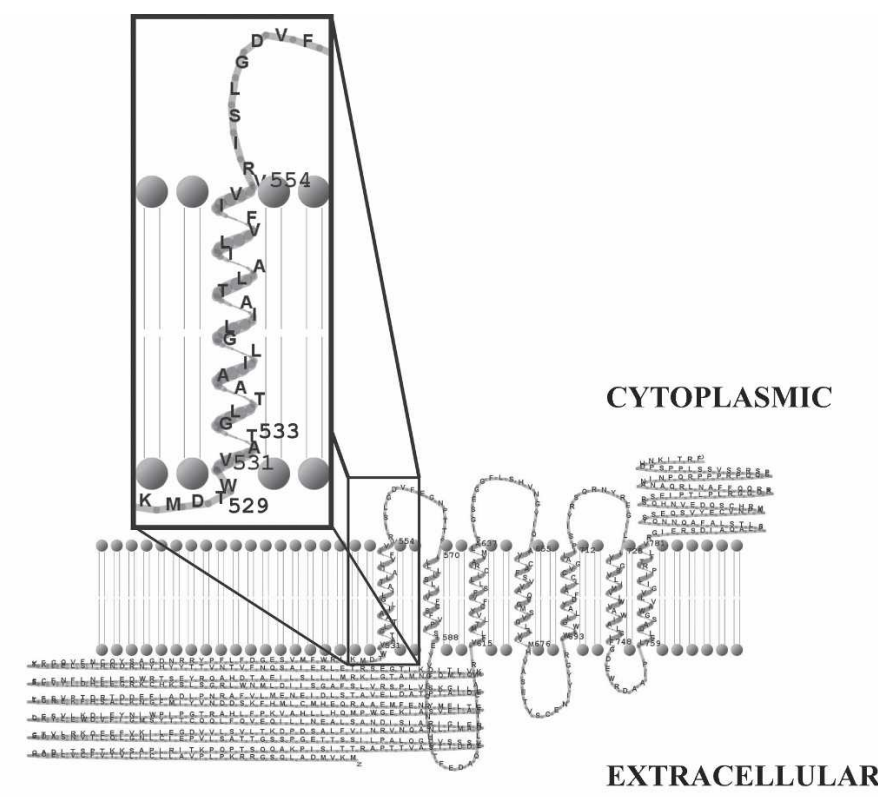

\begin{tabular}{|llllll|}
\hline D & T529A & W & V & A & T533A \\
\hline
\end{tabular}

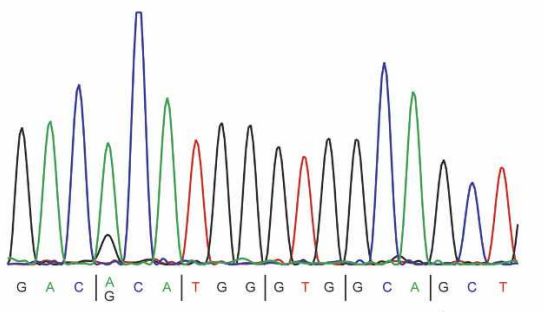

Genome DNA
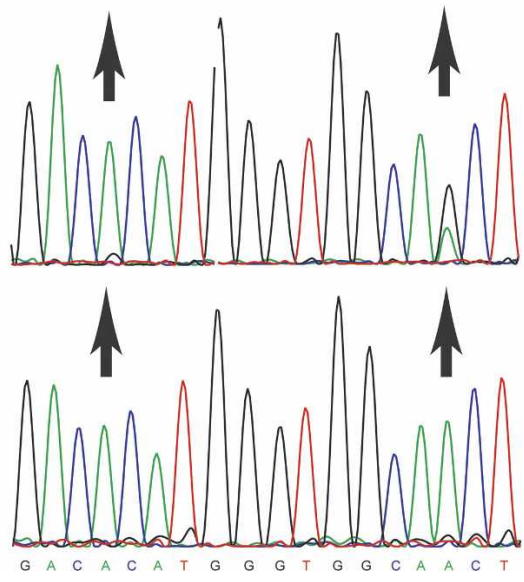

FIGURE 2. (Legend on next page) 
staple@fruitfly.org). Similar analysis was performed on a subset of these 27 new targets using RNA isolated from $A D A R$-deficient animals, and all sites tested $(n=23)$ showed shown). Although this method of measuring the ratio of edited and unedited transcripts has been reported to be accurate to as low as 5\% editing (Palladino et al. 2000), it cannot be used to determine the relative distribution of sites in cases where a transcript contains more than one edited site.

\section{New targets of dADAR}

The 27 new targets of ADAR are categorized into seven classes of genes, which are listed in Table 1. The seven gene classes include vesicular trafficking, ion homeostasis, signal transduction, ion channels, cytoskeletal components, an "other" class, and a novel or unknown class. For each target, the gene symbol, the cDNA representative that initially suggested editing, the protein, the amino acid residue(s), and $3^{\prime}$-UTR nucleotide(s) that are affected, along with the molecular function, if known, are listed.

The vesicular traffic class of targets contains six genes, Rab26, Rlip, rab3-GEF, endophilin A (endoA), $\alpha$-Adaptin, and sunday driver (syd). Small Ras-like G-proteins and their effectors are well-documented proteins that function in the intracellular transport of vesicles (Takai et al. 2001). Three of the six members fall into this category and are repreprotein Rlip, and the Rab3 guanyl-nucleotide exchange factor Rab3-GEF. The endoA and $\alpha$-Adaptin genes encode proteins that are involved in the endocytic pathway: endoA promotes synaptic vesicle budding, and $\alpha$-Adaptin is a subunit of the AP-2 complex (Guichet et al. 2002; Jafar-Nejad et al. 2002; Seto et al. 2002). The protein encoded by the syd gene was identified in a genetic screen in Drosophila for proteins involved in the axonal transport process (Bowman et al. 2000). Flies carrying mutations in syd reveal massive accumulations of various axonal membrane-bound cargoes, as well as axonal transport motors such as kinesin-I within the larval segmental nerves of multiple independent syd alleles. Syd is thought to function as a cargo adaptor in axonal transport by interacting directly with the kinesin light chain. a pure A signal, indicating the unedited transcript (data not sented by the GTPase Rab26, the Ral GTPase activator

The ion homeostasis class consists of five genes involved in sodium and calcium ion exchange and calcium sequestration. Members of this group represent a new class of molecules that serve as substrates for ADAR and include Calphotin (Cpn), Nckx30C, and the related CG1090, $\mathrm{Na}$ pump $\alpha$-subunit (Atp $\alpha)$, and CG32699. Atp $\alpha$ encodes a sodium:potassium-exchanging ATPase that undergoes a tyrosine-to-cysteine substitution due to editing. The Y390C substitution lies within the ATP hydrolase domain. The Atp $\alpha$ protein is predicted to contain 10 transmembrane-spanning segments and is detected in a subset of medial and lateral ventral cord neurons as well as in other larval and adult Drosophila tissues (Lebovitz et al. 1989). Animals carrying mutations in Atp $\alpha$ have behavioral abnormalities, reduced life span, and severe neuronal hyperexcitability along with the occurrence of age-dependent neurodegeneration (Palladino et al. 2003). The two related genes Nckx30C and CG1090 encode for proteins that function as potassium-dependent sodium-calcium exchangers. Nckx30C is critical for the rapid extrusion of calcium and is expressed in adult neurons and during ventral nerve cord development in the embryo (HaugCollet et al. 1999). Cpn encodes a photoreceptor cellspecific calcium ion binding protein (Ballinger et al. 1993; Martin et al. 1993), and CG32699 is a gene that has an assigned GO functional attribute as having "calcium ion binding with acyltransferase activity."

The signal transduction and ion channel groups contain two members each. The genes Mob1 and boss are grouped as signaling molecules, while the genes $S K$ and CG31116 are ion channels. The G-protein-coupled receptor boss and the two ion channels are discussed in greater detail in the next section. Mob1 encodes a highly conserved protein shown to genetically and physically interact with Tricornered $(\operatorname{trc})$, which is a member of the Drosophila Nuclear Dbf2 related (Ndr) subfamily of serine/threonine protein kinases (He et al. 2005). trc is required for the normal morphogenesis of polarized outgrowths such as epidermal hairs, sensory bristles, arista laterals, and sensory neuron dendrites (Geng et al. 2000; He and Adler 2002; Emoto et al. 2004). Furthermore, mutations in Mobl were isolated in a behavioral screen for genes involved in long-term memory (Dubnau et al. 2003).

Another unique class of edited target

FIGURE 2. Structure and editing of boss. (A) The transmembrane protein bride of sevenless (boss) is portrayed in the background and is predicted to pass through the lipid bilayer seven times with a large extracellular domain. An enlargement of the region found to be edited is in the boxed foreground. Threonines 529 and 533 lie at the junction between the extracellular and the first transmembrane domains, which, when edited by ADAR, are recoded to alanines. Representation of boss was visualized with TMRPres2D (Spyropoulos et al. 2004), a tool used for modeling transmembrane proteins. (B) Sequence chromatograms of the edited region of boss. The upper panel is a sequence trace from RTPCR products of boss from wild-type animals that shows a mixed signal of A and G at threonine 529 when compared to the trace derived from the control genomic DNA (lower panel). Threonine 533 appears to be completely edited and displays a pure $\mathrm{G}$ signal in the wild-type trace when compared to the genomic trace. The larval chromatogram in the middle panel displays an intermediate level of editing at these two positions, suggesting that editing of boss is developmentally regulated. The open box at the top is the protein translation with the edited threonine codons indicated. genes is involved in actin nucleation and organization, represented by spire (spir), Ataxin 2 (Atx2), and CG32809. spir belongs to the posterior group of genes and is required for properly specifying the axis in the developing oocyte and embryo (Manseau and Schupbach 1989). spir mutants have a defect in microtubule plus-end orientation during oogenesis (Wellington et al. 1999). Recently, the gene product, 
TABLE 1. New targets of ADAR editing

\begin{tabular}{|c|c|c|c|c|c|c|}
\hline Gene class & Symbol & cDNA & Protein & Residue change $^{a}$ & $3^{\prime}-U T R^{b}$ & Molecular function \\
\hline \multirow[t]{6}{*}{ Vesicular traffic } & Rab26 & GH21984 & CG7605-PA & K365R & & GTPase (Yoshie et al. 2000) \\
\hline & Rlip & GH01995 & CG11622-PA & $\begin{array}{l}\text { I229V, E230G, K233E, } \\
\text { E254G, K265R }\end{array}$ & $\begin{array}{c}2478,2480,2482 \\
2486,2740\end{array}$ & $\begin{array}{l}\text { Ral GTPase activator (Jullien-Flores } \\
\text { et al. 2000) }\end{array}$ \\
\hline & rab3-GEF & HL01222 & CG5627-PA & Q2022R, S2054G & 1306 & $\begin{array}{l}\text { Rab guanyl-nucleotide exchange factor } \\
\text { (Lloyd et al. 2000) }\end{array}$ \\
\hline & endoA & GH12907 & CG14296-PA & K129R, K137E & & $\begin{array}{l}\text { Promotes synaptic vesicle budding } \\
\text { (Verstreken et al. 2002) }\end{array}$ \\
\hline & \multicolumn{2}{|c|}{$\alpha$-AdaptinRH30202 } & CG4260-PA & T207A & & $\begin{array}{l}\text { Component of endocytosis, subunit of } \\
\text { AP-2 (Gonzalez-Gaitan and Jackle 1997) }\end{array}$ \\
\hline & syd & GH19969 & CG8110-PA & S983G & & $\begin{array}{l}\text { Kinesin-dependent axonal transport } \\
\text { (Bowman et al. 2000) }\end{array}$ \\
\hline \multirow[t]{5}{*}{ Ion homeostasis } & Cpn & GH08002 & CG4795-PB & S402G & & $\begin{array}{l}\mathrm{Ca}^{+2} \text { sequestration (Ballinger et al. } \\
\text { 1993; Martin et al. 1993) }\end{array}$ \\
\hline & Nckx30C & $\begin{array}{l}\text { HL01989, } \\
\text { GH04818 }\end{array}$ & CG18860-PC & K365R & & $\begin{array}{l}\mathrm{K}^{+} \text {-dependent } \mathrm{Na}^{+}, \mathrm{Ca}^{2+} \text { antiporter } \\
\text { (Haug-Collet et al. 1999) }\end{array}$ \\
\hline & CG1090 & GH23040 & CG1090-PA & L357L, S358G, L387L & & $\begin{array}{l}\mathrm{K}^{+} \text {-dependent } \mathrm{Na}^{+}, \mathrm{Ca}^{2+} \text { antiporter } \\
\text { (Webel et al. 2002) }\end{array}$ \\
\hline & Atp $\alpha$ & $\mathrm{GH} 23483$ & CG5670-PD & Y390C & & $\begin{array}{l}\mathrm{Na}^{+}, \mathrm{K}^{+} \text {exchanging ATPase (Palladino } \\
\text { et al. 2003) }\end{array}$ \\
\hline & \multicolumn{2}{|c|}{ CG32699 HL01250 } & CG32699-PA & $1175 \mathrm{M}$ & & $\mathrm{Ca}^{+2}$ binding, acyltransferase activity ${ }^{\mathrm{C}}$ \\
\hline \multirow{2}{*}{\multicolumn{2}{|c|}{$\begin{array}{c}\text { Signal transductionMob1 } \\
\text { boss }\end{array}$}} & RH70633 & CG11711-PD & N91D & & Activator of Trc kinase (He et al. 2005) \\
\hline & & GH10049 & CG8285-PA & T529A, T533A & & $\begin{array}{l}\text { G-protein-coupled receptor (Reinke and } \\
\text { Zipursky 1988; Kramer et al. 1991) }\end{array}$ \\
\hline \multirow[t]{2}{*}{ Ion channel } & SK & GH16664 & CG10706-PD & Y377C & \multirow[t]{2}{*}{2788} & $\mathrm{~K}^{+}$channel (Kohler et al. 1996) \\
\hline & CG31116 & $6 \mathrm{GH} 23529$ & CG31116-PA & $\begin{array}{l}\text { K232R, T259A, } \\
\text { K268R, E269G }\end{array}$ & & $\mathrm{Cl}^{-}$channel (Jentsch et al. 2005a) \\
\hline \multirow[t]{3}{*}{$\begin{array}{l}\text { Cytoskeletal } \\
\text { components }\end{array}$} & spir & $\mathrm{GH} 13327$ & CG10076-PC & K339R & & $\begin{array}{l}\text { Actin nucleation factor (Quinlan et al. } \\
\text { 2005) }\end{array}$ \\
\hline & Atx2 & GH01409 & CG5166-PA & K320R, K337R & & $\begin{array}{l}\text { Regulator of actin filament formation } \\
\text { (Satterfield et al. 2002) }\end{array}$ \\
\hline & \multicolumn{3}{|c|}{$\begin{array}{c}\text { CG32245 GH04632, CG32245-PB } \\
\text { GH25458 }\end{array}$} & R296R, N297D & $\begin{array}{l}2225,2248, \\
2249,2656\end{array}$ & Structural constituent of cytoskeleton ${ }^{c}$ \\
\hline \multirow[t]{2}{*}{ Other } & \multicolumn{2}{|c|}{ CG32809GH23439 } & CG32809-PB & K179R & & ATP binding ${ }^{c}$ \\
\hline & retm & GH05975 & CG9528-PA & Q245R & & Phosphatidylinositol transporter ${ }^{\mathrm{C}}$ \\
\hline \multirow[t]{7}{*}{ Unknown } & CG1552 & GH14443 & CG1552-PA & K121R & & None \\
\hline & \multicolumn{2}{|c|}{ CG31531GH25780 } & CG31531-PB & K679E & & None \\
\hline & CG3556 & GH17087 & CG3556-PA & $1572 \mathrm{~V}$ & & None \\
\hline & \multicolumn{2}{|c|}{ CG9801 GH23026 } & CG9801-PA & S345G & & None \\
\hline & \multicolumn{2}{|c|}{ I(1)G0196GH02989 } & CG14616-PC & $\begin{array}{l}\text { Q1148R, S1172G, } \\
\text { Q1176R }\end{array}$ & & None $^{d}$ \\
\hline & \multirow{2}{*}{\multicolumn{2}{|c|}{$\begin{array}{l}\text { CG12001 HL01040 } \\
\text { CG30079 HL05615 }\end{array}$}} & CG12001-PA & $1325 \mathrm{~V}$ & & None \\
\hline & & & CG30079-PA & $\begin{array}{l}\text { I127M, T303A, Q343R, } \\
\text { Q358R, S360G }\end{array}$ & & None \\
\hline
\end{tabular}

Spir, has been shown to nucleate actin filaments in a unique way and may be a novel link between actin organization and intracellular vesicle transport (Kerkhoff et al. 2001; Quinlan et al. 2005). The amino acid change in Spir introduced by editing lies between two important con- served domains, the FYVE domain and the Spir box, which have been shown to be involved in its localization on intracellular membranes and possible association with Rab11, respectively. Whether this ADAR-modified residue in Spir alters its ability to nucleate actin filaments has yet to 
be shown. Another target of ADAR in this class, Atx2, is not implicated in actin nucleation or polymerization, but rather as a possible regulator of specific mRNAs that function to mediate the formation of actin filaments. Atx2 is the Drosophila homolog of the human polyglutamine disease gene $S C A 2$, which is responsible for the dominantly inherited neurodegenerative disorder spinocerebellar ataxia type 2 (Huynh et al. 2000; Satterfield et al. 2002). In Drosophila, loss-of-function mutants of Atx2 suggest that its principal function is to regulate the formation or bundling of actin filaments by regulating a subset of RNA transcripts that encode mediators of actin filament formation. Studies of the SCA2 homolog, ATX-2, in C. elegans, demonstrate that it forms a complex with the poly(A)-binding protein $\mathrm{PAB}-1$ and functions in translational regulation in the development of the germline (Ciosk et al. 2004). The last member in this class is CG32245 and is placed here only through its associated GO functional attribute of "structural constituent of cytoskeleton."

There are two genes that comprise the "other" class, CG32809 and realtime (retm). CG32809 encodes a novel protein that is classified by GO as a protontransporting ATPase. It also contains a partial Actin interacting protein 3 domain (AIP3, pfam03915) identified using the CD-Search engine at the National Center for Biotechnology Information (NCBI) (Marchler-Bauer and Bryant 2004). However, the K179R substitution due to editing of this transcript does not lie near the AIP3 domain. The gene retm has an assigned function as a phosphatidylinositol transporter whose protein contains SEC14 (cd00170), MSF1 (pfam04707), and CRAL_TRIO_N (pfam03765) domains. retm belongs to a novel family of mitochondrial proteins, is expressed in the developing midgut and central nervous system during embryogenesis, and is subcellularly localized to mitochondria (Dee and Moffat 2005).

The largest class of genes identified has no assigned function in the GO database and contains seven members (Table 1). Although this class does not have any associated GO attributes, mutations do exist for one of its members. Mutations in CG14616 result in lethality during the first and second instar larval stages (Drysdale and Crosby 2005).

C

D

E

\section{Functional consequences of editing targets}

Three notable targets of ADAR are the integral membranespanning proteins encoded by the genes boss, CG31116, and $S K$. The G-protein-coupled receptor boss is unique in that it acts as a ligand to determine the fate of the R7 photoreceptor cell in the Drosophila compound eye by a specific inductive interaction between the boss-bearing R8 photoreceptor neuron and the R7 precursor cell (Fortini et al. 1992; Hart et al. 1993). Interestingly, the edited sites convert threonines 529 and 533 to alanines, which lie at the junction of the large extracellular domain and the first transmembrane domain (Fig. 2A). At the larval stage, the T533 codon
A

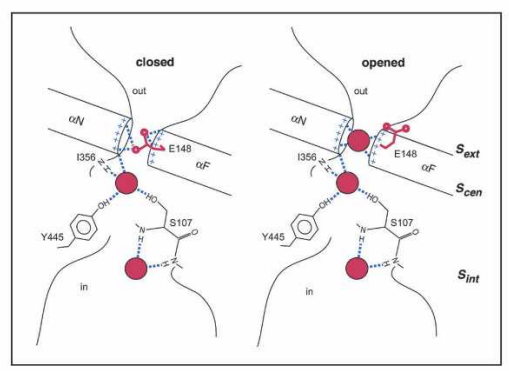

B

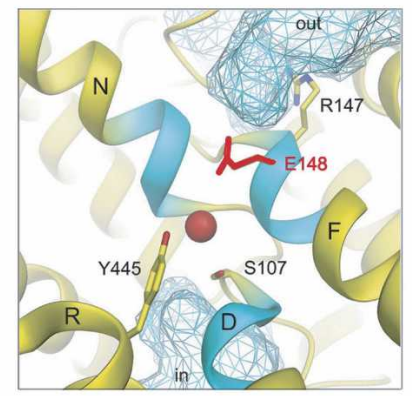

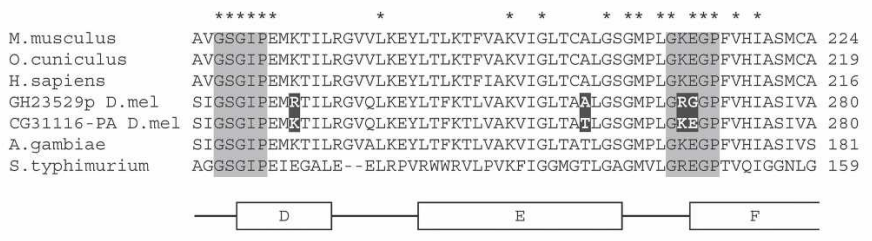

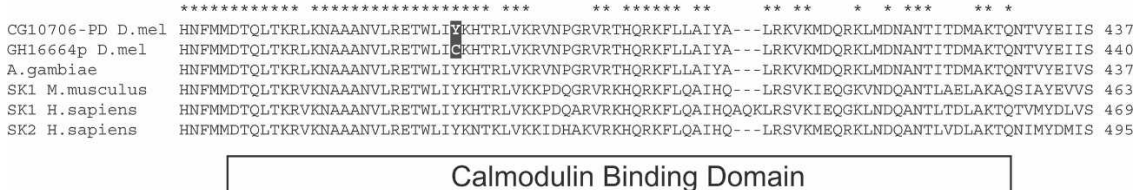

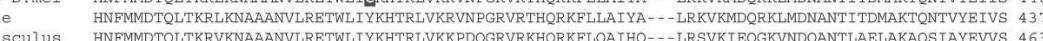
FMMDTQLTKRVKNAAAANVIRETWLIYKNTKIVYKTDHAKVRKHORKFLOAIHO--- -LRSVKMEQRKLNDQANTLVDLAKTONIMYDMIS $49^{\circ}$ Calmodulin Binding Domain

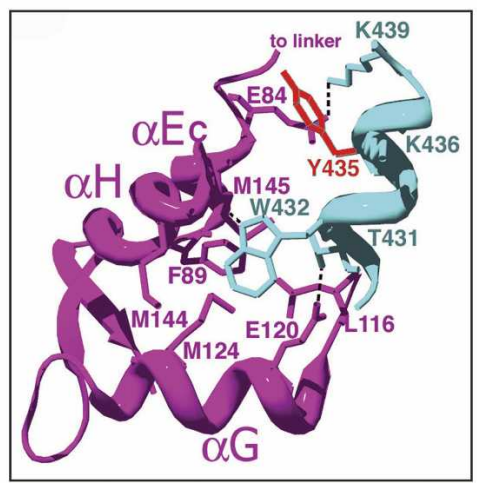

FIGURE 3. (Legend on next page) 
is a mix of signals, whereas in the adult, the T533 codon contains a pure $G$ signal, indicating this is likely the predominant form of boss in the adult fly (Fig. 2B). Furthermore, this suggests that editing of boss at these sites is developmentally regulated. These substitutions may have an effect on the way in which the R8 photoreceptor cell presents boss to neighboring R7 cells, potentially modifying the action of boss at later stages in eye development.

The gene CG31116 encodes a chloride channel belonging to the highly conserved $\mathrm{ClC}$ chloride channel family. In humans, mutations of $\mathrm{ClC}$ family members are associated with and underlying myotonia, Dent's disease, Bartter syndrome, osteoporosis, neurodegeneration, and possibly $\mathrm{K}^{+}$channels, possess structurally distinct elements that perform the selective conduction of ions (filtering) and the actual opening or closing of the pore (gating) (Jiang et al. 2002). Crystallographic and electrophysiological studies of the anionic $\mathrm{ClC}$ channels from Escherichia coli and Salmonella typhimurium elegantly show that the processes of gating and filtering are closely tied (Dutzler et al. 2002) and that the side-chain carboxyl group of a glutamate residue serves as the gate of the pore lying within the selectivity filter (Fig. $3 \mathrm{~A}, \mathrm{~B})$. Obstructing the pore with its side chain closes the pore, while binding of a $\mathrm{Cl}^{-}$ion opens it. We have identified four edited sites, two of which affect residues in the selectivity filter (Fig. 3C). One of these residues is the highly conserved glutamate residue whose side chain acts as the epilepsy (Jentsch et al. 2005b). Some ion channels, such as

anionic gate. We have found this glutamate codon to be edited in $\sim 10 \%$ of the adult head transcripts to encode a Gly residue, which interestingly is a residue that does not contain the carboxyl side chain capable of closing the ion pore and would be consistent with an open pore conformation. Electrophysiologic and crystallographic studies testing channel function support this observation. Converting the glutamate residue in the Torpedo ray ClC-0 channel to Ala, Gln, or Val causes the channel gate to stay open (Dutzler et al. 2003). Moreover, CG31116 is expressed in the ventral nerve cord, lateral cord glia, and the ventral midline, consistent with a neuronal function (Kearney et al. 2004).

Another striking example of putative functional consequences of RNA editing on protein function is the transcript for the gene $S K$. This gene encodes a voltage-independent ion channel that is activated by submicromolar concentrations of intracellular calcium. These channels are highaffinity calcium sensors that transduce fluctuations in calcium concentrations into changes in membrane potential. SK channels are not gated by direct calcium binding, but are heteromeric complexes with calmodulin (CaM), where gating is mediated by binding of calcium to calmodulin and subsequent conformational alterations in the channel protein (Xia et al. 1998). The edited form of the SK transcript results in the tyrosine at position 377 being converted to a cysteine. This Y377C substitution is directly within the highly conserved calmodulin-binding domain (CaMBD) (Fig. 3D). The crystal structure of the CaMBD from rat SK2 complexed with apoCal-

FIGURE 3. Structure and editing of $\mathrm{ClC}$ and SK ion channels. (A) Schematic of a ClC chloride channel conductance filter showing the closed and open conformations. The chloride ion is represented by red spheres, and the glutamate side chain is shown in red. Notice in the closed configuration the glutamate 148 side chain is occupying the ion binding site, while in the open configuration, it has moved out of the site and is replaced by a $\mathrm{Cl}^{-}$ion. Reprinted (with permission from AAAS (C) 2003) from Dutzler et al. (2003). (B) Ribbon structure of the ClC conductance filter depicted in the closed configuration with a chloride ion shown as a red sphere with the side chain of the edited glutamate 148 colored red. The amino acids at the ends of the $\alpha$-helices, including the glutamate 148 at the end of helix F, are brought together near the membrane center to form the ion-binding site, shown in light blue. The vestibules toward the interior and exterior of the membrane are depicted as hatched domains. Reprinted (with permission from Macmillan Publishers Ltd. (C) 2002, http://www.nature.com/nature/ index.html) from Dutzler et al. (2002). (C) Sequence alignment of the edited portion of ClC channels. Residues from the $\mathrm{Cl}^{-}$selectivity filter are represented by the gray shaded boxes, and identical residues are indicated with an asterisk. The four residues whose codons are edited in D. melanogaster are indicated by black boxes. The $\alpha$-helices are depicted as open boxes below the alignment. The amino acid sequences and GenBank numbers are Mus musculus ClC2, NP_034030.1; Oryctolagus cuniculus ClC2, AAB05937.1; Homo sapiens ClC2, AAB34722.2; D. melanogaster GH23529p, AAM50193.1; D. melanogaster CG31116-PA, AAF54701.3; Anopheles gambiae, XP_312021.2; S. typhimurium, AE008704. The sequence alignments were performed with CLUSTALX (Thompson et al. 1997). (D) Sequence alignment of the Calmodulin binding domain of SK channels. The tyrosine 377 residue whose codon is edited in D. melanogaster is indicated by a black box. Identical residues are indicated with an asterisk, and the Calmodulin binding domain is depicted as an open box below the alignment. The amino acid sequences and GenBank numbers are D. melanogaster CG10706-PD, NP_726987.1; D. melanogaster GH16664p, AAM50183.1; A. gambiae, XP_314474.2; M. musculus SK1, AAK48900.1; H. sapiens SK1, AAH75037.3; H. sapiens SK2, AAP45946.1. The sequence alignments were performed with CLUSTALX (Thompson et al. 1997). (E) Ribbon structure of the rat SK2 calmodulin binding domain (colored in light blue) complexed with the apoCalmodulin C lobe (in purple). Notice that tyrosine 435 (colored in red) of SK2, which is the highly conserved tyrosine 377 in D. melanogaster, is involved in the interaction with apoCalmodulin. Reprinted (with permission from Elsevier (c) 2004) from Schumacher et al. (2004). modulin reveals that the key region of CaMBD involved in apoCaM binding consists of 10 residues, which form an $\alpha$-helix that binds only the C lobe of CaM (Schumacher et al. 2001). Interestingly, the structure suggests a van der Waals contact between the side chain of Y435 and residues in the $\mathrm{E}$ and $\mathrm{H} \alpha$ helix of CaM (Fig. 3E). Tyrosine 435 in the rat SK2 channel is the cognate tyrosine at position 377 that is edited in the Drosophila SK channel. Whether this Y377C substitution has a functional role in the ability of calmodulin to bind to the channel and therefore affect the transductive capacity of calmodulin remains to be tested.

Editing in D. melanogaster is thought to be a gene sparing strategy. That is, a different form of the same protein is used at different times in the animal's life cycle to perform similar functions and is facilitated by the differential activities of ADAR throughout development (Keegan et al. 2005). Our observations, including the example of 
TABLE 2. Primer pairs for RT-PCR

\begin{tabular}{|c|c|}
\hline Gene & Sense primer/antisense primers for RT-PCR \\
\hline CG10076 & 5'-CAGAGCAACCTGGACGAGA-3'/5' -TTCGCATCTTGGTATAGCA-3' \\
\hline CG10706 & 5'-CTCTAATGACAATATGTCCGGG-3'/5'-TGTGTTTGCATTATCCATTAGT-3' \\
\hline CG1090 & 5'-CTGGTTTCCTGGTACGTGGT-3'/5'-TATTACGTTGACGTGCGAGC-3' \\
\hline CG11622 & 5'-AGTGCTGGCACTTGGGTATC-3'/5'-ATTGCACTTGGGCAATTGTT-3' \\
\hline CG11711 & 5'-GAGTTCTCCTCCATTAGCCAA-3'/5'-AGTCCAAACCAGCTGGAAG-3' \\
\hline CG12001 & 5'-TTTCTTGACCTGTTGGAGGC-3'/5'-TGTCGTAGCCAAATCCCTTC-3' \\
\hline CG14296 & 5'-GATCAACAAGGCCAACCAGT-3'/5'-TGGCTCCAAAAAGTTCTGCT-3' \\
\hline CG14616 & 5'-CTAAACGAGGAGCTGGCATC-3'/5'-TTGCTAAAACCACCGAAACC-3' \\
\hline CG1552 & 5'-GCCTCGTCCTTTTGAGCCT-3'/5'-TGAGGAGCGAGTTATTGGG-3' \\
\hline CG18860 & 5'-AACTCGACCACCACGAAAAC-3'/5'-GATCAGCACCAGCAAACTGA-3' \\
\hline CG30079_1 & 5'-TGCGAAACCCTCCAGAAAC-3'/5'-CGGTGAGGGATACGTTTGCT-3' \\
\hline CG30079_2 & 5'-CGCGTTACCAGCCCATCC-3'/5'-TGATCTGGGGTATGGATAGCG-3' \\
\hline CG31116 & 5'-GATCTGACGTCACAGCCTTTTG-3'/5'-TGGAATGATGTGACAAGTTTAC-3' \\
\hline CG31531 & 5'-GCGGTCAACCAAATTGAA-3'/5'-CTGGGTAGGAATCGGAGT-3' \\
\hline CG32245 & 5'-TATCTTCCGTTTGGGTCGTC-3'/5'-CGTCATACGCTCGCTGAGTA-3' \\
\hline CG32699 & 5'-CAAATGCAATACATGACGGC-3'/5' -GGCGTAATACTCCAGGTCCA-3' \\
\hline CG32809 & 5'-GAAAACTCTGGAACGACCG-3'/5'-TTCCGTTCTGAAGAGTACA-3' \\
\hline CG3556 & 5'-CCGAAATGGATCCCAGATT-3'/5' -TTGATTACGCCATTATTAT-3' \\
\hline CG4260 & 5'-TTCCAACGAAATACCCAAGC-3'/5'-GTAGTTTTGCAGCAATCGCA-3' \\
\hline CG4795 & 5'-GTGCTTCGACTGAGCCCC-3'/5'-GCCGTAGTTGGTGGAGTA-3' \\
\hline CG5166 & 5'-ACCGCAGCTATCGCATGT-3'/5'-CGCCCATGTGAGATTGGT-3' \\
\hline CG5627 & 5'-GGCCATTTCACGTAGCGG-3'/5'-CACAGCCAGGGGATACAGA-3' \\
\hline CG5670 & 5'-GGCTGGACGCTGTCATCTT-3'/5'-CGGCAATCTTCTTATTACG-3' \\
\hline CG7605 & 5'-GAGTACGCGCAGGAGGAC-3'/5' -CGGGCTTATTGTTGTCTT-3' \\
\hline CG8110 & 5'-AATCGCTGAACCCCATACTG-3'/5'-GAGGCAACGTATCGAATGGT-3' \\
\hline CG8285 & 5'-CCСATGATACGGCTGAGAT-3'/5'-TGCTCACCCACGTATTCAA-3' \\
\hline CG9528 & 5'-GATCAGCAGCATAGCATCTTG-3'/5'-CGGCGGATTCATTGATCTTCT-3' \\
\hline CG9801 & 5'-TGCGACTTCGCATATGGT-3'/5'-CTCAGCTCTGGCTTGTTG-3' \\
\hline CG11622_UTR & 5'-CСTCСTTGGCCTCGGGAT-3'/5'-CGCCGTTTAACAGTAATTATAGTTTGAA-3' \\
\hline CG5627_UTR & 5'-ATCGATGTCATCATCATCCG-3'/5'-GGACTTACAAATGTTTTAACAATTTTGAA-3' \\
\hline CG10706_UTR & 5'-AACGGCCATCACATTTCTGT-3'/5' -CCAATGATATTTCCCCATTCC-3' \\
\hline CG32245_UTR1 & 5'-CCGCAGCAGCAAGATCAA-3'/5'-AGATCCCTCGTTTCTTTCTTGA-3' \\
\hline CG32245_UTR2 & 5'-TTGAGTTACTATCCTTTAGGAAATGCT-3'/5' -TGTCAACAGTTCATTGAATATTTTGG-3' \\
\hline CG32245_UTR3 & 5'-AACCAGTTTTGAAAGTCTTGAATTG-3'/5'-AATTAAGGTGTCAATTGGTAAAACAGT-3' \\
\hline CG32245_UTR4 & 5'-AATACAACTGTTAATCTGTTTCCACTG-3'/5'-GCTCTTTTTGGATACCAAAAAAGTTGAAGAAAT-3' \\
\hline
\end{tabular}

the effect on $\mathrm{Cl}^{-}$gating, the possible developmental alteration of the activity of the boss ligand, and the other possible functional implications of editing in the $3^{\prime}$ UTRs, suggest an even greater role of editing by modulating specific protein function and transcript stability. It is very likely that more targets of editing exist in Drosophila because the bias of our sampling method was limited to the abundant mRNAs represented in our cDNA libraries coupled with the observation that editing is not $100 \%$ efficient. In summary, this analysis has identified 38 editing targets, 27 newly discovered, which doubles the total number of editing targets in D. melanogaster to 55 .

\section{MATERIALS AND METHODS}

\section{Identification of putative ADAR editing targets}

We compared the nucleotide sequence of all full-length cDNA clones derived from libraries of adult head tissue to the Release 4 genome sequence and to the Release 4.1 computed gene models. Using Sim4 (Florea et al. 1998), we recorded all A $>$ G substitutions, then manually inspected each clone for sequence quality discrepancies and Sim 4 artifacts using Consed Autofinish (Gordon et al. 2001). This produced a curated list of 108 genes that were chosen as candidates for experimental testing.

\section{Validation of targets}

We used a similar method for RNA isolation and RT-PCR described previously (Stapleton et al. 2002a). RNA and genomic DNA were isolated at the same time using the Trizol reagent (Invitrogen) from adult heads from the isogenic strain $y^{1} ; c n^{1} b w^{1}$ $s p^{l}$. For the boss analysis, we isolated RNA from 0-24-h embryos, a mixed stage of larvae, and pupae from the isogenic strain. RTPCR amplicons of the boss region from embryo and pupal RNA were negative, but positive for the larva RNA. RNA preps were digested with RNAase-free DNAase I (Roche) and tested by PCR to ensure the absence of contaminating genomic DNA. We designed gene-specific primers for the RT-PCR and the genomic PCR amplifications using Primer3 (Rozen and Skaletsky 2000) and the primer-picking feature in Consed Autofinish. The 
TABLE 3. Primer pairs for genomic PCR

\begin{tabular}{|c|c|}
\hline Gene & Sense primer/antisense primers for genomic PCR \\
\hline CG10076 & 5'-TAAGAGAAGTCCTGCGGAGC-3'/5'-ATCAACGACTTGGGGAACTG-3' \\
\hline CG10706 & 5'-GCAGTTGACGAAACGGGTAT-3'/5' -ATTTCCCCATTCCAAAGACC-3' \\
\hline CG1090 & 5'-TCAGGAAAACATGGGCTACC-3'/5' -TATTACGTTGACGTGCGAGC-3' \\
\hline CG11622 & 5'-CCCACAAGGTCAAGGAGAAA-3'/5'-ATTGCACTTGGGCAATTGTT-3' \\
\hline CG11711 & 5'-GCСАСТССТTACCGACAGAA-3'/5'-AGCGTTTAGTTCCCCCAGTT-3' \\
\hline CG12001 & 5'-GCAATGCATTTGGTTTGATG-3'/5'-AGCTACCATACTTCCGCCCT-3' \\
\hline CG14296 & 5'-GATCAACAAGGCCAACCAGT-3'/5'-CCACGAATCTCATCGTCCTT-3' \\
\hline CG14616 & 5'-GAGACATCGCTCCTACAGCC-3'/5' -CCGGAAGAGGAGACCGTTAT-3' \\
\hline CG1552 & 5'-TTGGTTCACAAATCGCAGAA-3'/5'-CACCCTAACCCAACCTAGCA-3' \\
\hline CG18860 & 5'-CTCCСGATTAAAGCCATCAA-3'/5' -CTAGCTTCCTGCTAATGCCG-3' \\
\hline CG30079_1 & 5'-AGAGCCCGTCAGTGAAGTGT-3'/5'-AAGGAGTGCGAAGAGAACGA-3' \\
\hline CG30079_2 & 5'-TGCTGCTCTTGATGTTCGAC-3'/5'-ACACTTCACTGACGGGCTCT-3' \\
\hline CG31116 & 5'-CCGCCAACATTTCAGAGTTT-3'/5'-GCACСTCСAATCTGAGAACC-3' \\
\hline CG31531 & 5'-ATTGCGGGACATGGAATTTA-3'/5' -TTAAAAATCTCCACACGCCC-3' \\
\hline CG32245 & 5'-CGGCTATAAAGTGCACAGCA-3'/5' -GCTCGACGAAGTCGCTAGAT-3' \\
\hline CG32699 & 5'-CAGCCAGAGAAGGCGTAATC-3'/5' -CAAATGCAATACATGACGGC-3' \\
\hline CG32809 & 5'-AAGCССТАСАTССТСАСССТ-3'/5's'-ATCATGTCGGAGGTGGAAAC-3' \\
\hline CG3556 & 5'-GGATCCCAGGTAAAACAGCA-3'/5' -ACCATTAGCTCGTCCACACC-3' \\
\hline CG4260 & 5'-GTAGTTTTGCAGCAATCGCA-3'/5' -TTCCAACGAAATACCCAAGC-3' \\
\hline CG4795 & 5'-TGTTGTAACTTCGACAGGCG-3'/5'-ACCTGTTGTTGCAGAAACCC-3' \\
\hline CG5166 & 5'-GGTGACTTCCAGTTGAGGGA-3'/5' -TTGCGAGTTACCCTGGTAGG-3' \\
\hline CG5627 & 5'-TACACCGCCACAGTATACGC-3'/5'-CACAGCCAGGGGATACAGAT-3' \\
\hline CG5670 & 5'-GATCCACCATTTCATCCACC-3'/5'-GTTCCATGCACTTGAGCAGA-3' \\
\hline CG7605 & 5'-TGTGGAGCTGTCCTTCACAG-3'/5'-ATCGGGAGGATATGGCTCTT-3' \\
\hline CG8110 & 5'-TACGTACGGCTCAATGTCCA-3'/5' -ACTGGAGACCAAGGATCGTG-3' \\
\hline CG8285 & 5'-AGATTGCGTCGCAGAACTTT-3'/5'-GGGTATTCAGAGTCTGGGCA-3' \\
\hline CG9528 & 5'-AAGTGTTCCACTACCACGGC-3'/5' -TGAAGCAGTACACCCAGACG-3' \\
\hline CG9801 & 5'-TTAGTTCCCGTACTCCGTGC-3'/5'-ATGGTGTCAACTGGGGTGAT-3' \\
\hline CG11622_UTR & 5'-TGGGCATGGAACTAAAGGAG-3'/5'-AGATTTCTTTGGGGCTTTGC-3' \\
\hline CG5627_UTR & 5'-CTTGTCATCATCCACATCGC-3'/5'-ACATGGATTAGGAAAGCCCC-3' \\
\hline CG10706_UTR & 5'-GCAGTTGACGAAACGGGTAT-3'/5'-CCAATGATATTTCCCCATTCC-3' \\
\hline CG32245_UTR1 & 5'-CCGCAGCAGCAAGATCAA-3'/5'-AGATCCCTCGTTTCTTTCTTGA-3' \\
\hline CG32245_UTR2 & 5'-TTGAGTTACTATCCTTTAGGAAATGCT-3'/5'-TGTCAACAGTTCATTGAATATTTTGG-3' \\
\hline CG32245_UTR3 & 5'-AACCAGTTTTGAAAGTCTTGAATTG-3'/5'-AATTAAGGTGTCAATTGGTAAAACAGT-3' \\
\hline CG32245_UTR4 & 5'-AATACAACTGTTAATCTGTTTCCACTG-3'/5' -GCTCTTTTGGATACCAAAAAAGTTGAAGAAAT-3' \\
\hline
\end{tabular}

sense/antisense primer pair sequences for regions of the 27 validated genes are shown in Tables 2 and 3

Previously, we cloned PCR products from multiple RT reactions in order to evaluate the potential for editing. However, in this report, we directly sequenced the PCR products. For sequencing, PCR products were treated with $0.3 \mu \mathrm{L}$ of Exonuclease I (USB), $0.5 \mu \mathrm{L}$ of Shrimp Alkaline Phosphatase (Roche), and 0.5 $\mu \mathrm{L}$ of $1 \mathrm{M}$ Tris (ph 8.0) in a final reaction volume of $75 \mu \mathrm{L}$ and incubated for $45 \mathrm{~min}$ at $37^{\circ} \mathrm{C}$ and then heat-inactivated for $10 \mathrm{~min}$ at $65^{\circ} \mathrm{C}$. The same sense and antisense primers used for RT-PCR and genomic PCR were used as sequencing primers in a $10-\mu \mathrm{L}$ reaction containing $1 \mu \mathrm{L}$ of $\mathrm{ABI}$ Big Dye III terminator mix (Applied Biosystems). Sequencing reactions were precipitated according to the manufacturer's protocol and loaded onto an ABI Prism 3730 DNA Analyzer. Sequence data were assembled and analyzed with the Phred/Phrap suite of programs and visualized with Consed. Chromatogram trace peaks at positions chosen for interrogation that displayed an unambiguous mixture of $A$ and $G$ signals or a pure $G$ signal were recorded as being a positive target of ADAR. For the RT-PCR amplicons that were ambiguous or weak, we cloned PCR products from two in- dependent RT-PCR reactions and picked 48 clones each for sequence analysis.

\section{ACKNOWLEDGMENTS}

We thank Gerry Rubin for providing support and encouragement; Ken Wan, Soo Park, and Richard Weiszmann for excellent technical support; and Roger Hoskins for critically reading and improving the manuscript. This work was supported by NIH grant HG002673 (to S.E.C.) and by the US Department of Energy under Contract No. DE-AC02-05CH11231.

Received August 7, 2006; accepted August 24, 2006.

\section{REFERENCES}

Ashburner, M., Ball, C.A., Blake, J.A., Botstein, D., Butler, H., Cherry, J.M., Davis, A.P., Dolinski, K., Dwight, S.S., Eppig, J.T., et al. The Gene Ontology Consortium. 2000. Gene Ontology: Tool for the unification of biology. Nat. Genet. 25: 25-29. 
Athanasiadis, A., Placido, D., Maas, S., Brown II, B.A., Lowenhaupt, K., and Rich, A. 2005. The crystal structure of the $Z \beta$ domain of the RNA-editing enzyme ADAR1 reveals distinct conserved surfaces among Z-domains. J. Mol. Biol. 351: 496-507.

Ballinger, D.G., Xue, N., and Harshman, K.D. 1993. A Drosophila photoreceptor cell-specific protein, calphotin, binds calcium and contains a leucine zipper. Proc. Natl. Acad. Sci. 90: 1536-1540.

Bass, B.L. 2002. RNA editing by adenosine deaminases that act on RNA. Annu. Rev. Biochem. 71: 817-846.

Bowman, A.B., Kamal, A., Ritchings, B.W., Philp, A.V., McGrail, M., Gindhart, J.G., and Goldstein, L.S. 2000. Kinesin-dependent axonal transport is mediated by the Sunday driver (SYD) protein. Cell 103: $583-594$.

Cho, D.S., Yang, W., Lee, J.T., Shiekhattar, R., Murray, J.M., and Nishikura, K. 2003. Requirement of dimerization for RNA editing activity of adenosine deaminases acting on RNA. J. Biol. Chem. 278: 17093-17102.

Ciosk, R., DePalma, M., and Priess, J.R. 2004. ATX-2, the C. elegans ortholog of ataxin 2, functions in translational regulation in the germline. Development 131: 4831-4841.

Dee, C.T. and Moffat, K.G. 2005. A novel family of mitochondrial proteins is represented by the Drosophila genes slmo, preli-like and real-time. Dev. Genes Evol. 215: 248-254.

Drysdale, R.A. and Crosby, M.A. 2005. FlyBase: Genes and gene models. Nucleic Acids Res. 33: D390-D395.

Dubnau, J., Chiang, A.S., Grady, L., Barditch, J., Gossweiler, S., McNeil, J., Smith, P., Buldoc, F., Scott, R., Certa, U., et al. 2003. The staufen/pumilio pathway is involved in Drosophila long-term memory. Curr. Biol. 13: 286-296.

Dutzler, R., Campbell, E.B., Cadene, M., Chait, B.T., and MacKinnon, R. 2002. X-Ray structure of a ClC chloride channel at $3.0 \AA$ reveals the molecular basis of anion selectivity. Nature 415: $287-294$.

Dutzler, R., Campbell, E.B., and MacKinnon, R. 2003. Gating the selectivity filter in $\mathrm{ClC}$ chloride channels. Science 300: 108-112.

Emoto, K., He, Y., Ye, B., Grueber, W.B., Adler, P.N., Jan, L.Y., and Jan, Y.N. 2004. Control of dendritic branching and tiling by the Tricornered-kinase/Furry signaling pathway in Drosophila sensory neurons. Cell 119: 245-256.

Florea, L., Hartzell, G., Zhang, Z., Rubin, G.M., and Miller, W. 1998. A computer program for aligning a cDNA sequence with a genomic DNA sequence. Genome Res. 8: 967-974.

Fortini, M.E., Simon, M.A., and Rubin, G.M. 1992. Signalling by the sevenless protein tyrosine kinase is mimicked by Ras1 activation. Nature 355: 559-561.

Geng, W., He, B., Wang, M., and Adler, P.N. 2000. The tricornered gene, which is required for the integrity of epidermal cell extensions, encodes the Drosophila nuclear DBF2-related kinase. Genetics 156: 1817-1828.

Gonzalez-Gaitan, M. and Jackle, H. 1997. Role of Drosophila $\alpha$-adaptin in presynaptic vesicle recycling. Cell 88: 767-776.

Gordon, D., Desmarais, C., and Green, P. 2001. Automated finishing with autofinish. Genome Res. 11: 614-625.

Guichet, A., Wucherpfennig, T., Dudu, V., Etter, S., WilschBrauniger, M., Hellwig, A., Gonzalez-Gaitan, M., Huttner, W.B., and Schmidt, A.A. 2002. Essential role of endophilin A in synaptic vesicle budding at the Drosophila neuromuscular junction. EMBO J. 21: 1661-1672.

Hart, A.C., Kramer, H., and Zipursky, S.L. 1993. Extracellular domain of the boss transmembrane ligand acts as an antagonist of the sev receptor. Nature 361: 732-736.

Haudenschild, B.L., Maydanovych, O., Veliz, E.A., Macbeth, M.R., Bass, B.L., and Beal, P.A. 2004. A transition state analogue for an RNA-editing reaction. J. Am. Chem. Soc. 126: 11213-11219.

Haug-Collet, K., Pearson, B., Webel, R., Szerencsei, R.T., Winkfein, R.J., Schnetkamp, P.P., and Colley, N.J. 1999. Cloning and characterization of a potassium-dependent sodium/calcium exchanger in Drosophila. J. Cell Biol. 147: 659-670.
He, B. and Adler, P.N. 2002. The genetic control of arista lateral morphogenesis in Drosophila. Dev. Genes Evol. 212: 218-229.

He, Y., Emoto, K., Fang, X., Ren, N., Tian, X., Jan, Y.N., and Adler, P.N. 2005. Drosophila Mob family proteins interact with the related tricornered $(\operatorname{Trc})$ and warts (Wts) kinases. Mol. Biol. Cell 16: 4139-4152.

Higuchi, M., Single, F.N., Kohler, M., Sommer, B., Sprengel, R., and Seeburg, P.H. 1993. RNA editing of AMPA receptor subunit GluRB: A base-paired intron-exon structure determines position and efficiency. Cell 75: 1361-1370.

Higuchi, M., Maas, S., Single, F.N., Hartner, J., Rozov, A., Burnashev, N., Feldmeyer, D., Sprengel, R., and Seeburg, P.H. 2000. Point mutation in an AMPA receptor gene rescues lethality in mice deficient in the RNA-editing enzyme ADAR2. Nature 406: 78-81.

Hoopengardner, B., Bhalla, T., Staber, C., and Reenan, R. 2003. Nervous system targets of RNA editing identified by comparative genomics. Science 301: 832-836.

Huynh, D.P., Figueroa, K., Hoang, N., and Pulst, S.M. 2000. Nuclear localization or inclusion body formation of ataxin-2 are not necessary for SCA2 pathogenesis in mouse or human. Nat. Genet. 26: $44-50$.

Jafar-Nejad, H., Norga, K., and Bellen, H. 2002. Numb: "Adapting" notch for endocytosis. Dev. Cell 3: 155-156.

Jentsch, T.J., Neagoe, I., and Scheel, O. 2005a. CLC chloride channels and transporters. Curr. Opin. Neurobiol. 15: 319-325.

Jentsch, T.J., Poet, M., Fuhrmann, J.C., and Zdebik, A.A. 2005b. Physiological functions of $\mathrm{CLC} \mathrm{Cl}^{-}$channels gleaned from human genetic disease and mouse models. Annu. Rev. Physiol. 67: 779-807.

Jiang, Y., Lee, A., Chen, J., Cadene, M., Chait, B.T., and MacKinnon, R. 2002. The open pore conformation of potassium channels. Nature 417: 523-526.

Jullien-Flores, V., Mahe, Y., Mirey, G., Leprince, C., MeunierBisceuil, B., Sorkin, A., and Camonis, J.H. 2000. RLIP76, an effector of the GTPase Ral, interacts with the AP2 complex: Involvement of the Ral pathway in receptor endocytosis. J. Cell Sci. 113: 2837-2844.

Kapranov, P., Cawley, S.E., Drenkow, J., Bekiranov, S., Strausberg, R.L., Fodor, S.P., and Gingeras, T.R. 2002. Large-scale transcriptional activity in chromosomes 21 and 22. Science 296: 916-919.

Kearney, J.B., Wheeler, S.R., Estes, P., Parente, B., and Crews, S.T. 2004. Gene expression profiling of the developing Drosophila CNS midline cells. Dev. Biol. 275: 473-492.

Keegan, L.P., Brindle, J., Gallo, A., Leroy, A., Reenan, R.A., and O'Connell, M.A. 2005. Tuning of RNA editing by ADAR is required in Drosophila. EMBO J. 24: 2183-2193.

Kerkhoff, E., Simpson, J.C., Leberfinger, C.B., Otto, I.M., Doerks, T., Bork, P., Rapp, U.R., Raabe, T., and Pepperkok, R. 2001. The Spir actin organizers are involved in vesicle transport processes. Curr. Biol. 11: 1963-1968.

Kim, D.D., Kim, T.T., Walsh, T., Kobayashi, Y., Matise, T.C., Buyske, S., and Gabriel, A. 2004. Widespread RNA editing of embedded alu elements in the human transcriptome. Genome Res. 14: 1719-1725.

Kohler, M., Hirschberg, B., Bond, C.T., Kinzie, J.M., Marrion, N.V., Maylie, J., and Adelman, J.P. 1996. Small-conductance, calciumactivated potassium channels from mammalian brain. Science 273: $1709-1714$.

Kramer, H., Cagan, R.L., and Zipursky, S.L. 1991. Interaction of bride of sevenless membrane-bound ligand and the sevenless tyrosinekinase receptor. Nature 352: 207-212.

Lai, E.C. 2005. miRNAs. Whys and wherefores of miRNA-mediated regulation. Curr. Biol. 15: R458-R460.

Lai, E.C., Tomancak, P., Williams, R.W., and Rubin, G.M. 2003. Computational identification of Drosophila microRNA genes. Genome Biol. 4: R42.

Leaman, D., Chen, P.Y., Fak, J., Yalcin, A., Pearce, M., Unnerstall, U., Marks, D.S., Sander, C., Tuschl, T., and Gaul, U. 2005. Antisensemediated depletion reveals essential and specific functions of microRNAs in Drosophila development. Cell 121: 1097-1108. 
Lebovitz, R.M., Takeyasu, K., and Fambrough, D.M. 1989. Molecular characterization and expression of the $\left(\mathrm{Na}^{+}+\mathrm{K}^{+}\right)$-ATPase $\alpha$-subunit in Drosophila melanogaster. EMBO J. 8: 193-202.

Levanon, E.Y., Eisenberg, E., Yelin, R., Nemzer, S., Hallegger, M., Shemesh, R., Fligelman, Z.Y., Shoshan, A., Pollock, S.R., Sztybel, D., et al. 2004. Systematic identification of abundant A-to-I editing sites in the human transcriptome. Nat. Biotechnol. 22: 1001-1005.

Lloyd, T.E., Verstreken, P., Ostrin, E.J., Phillippi, A., Lichtarge, O., and Bellen, H.J. 2000. A genome-wide search for synaptic vesicle cycle proteins in Drosophila. Neuron 26: 45-50.

Macbeth, M.R., Schubert, H.L., Vandemark, A.P., Lingam, A.T., Hill, C.P., and Bass, B.L. 2005. Inositol hexakisphosphate is bound in the ADAR2 core and required for RNA editing. Science 309: $1534-1539$.

Manseau, L.J. and Schupbach, T. 1989. cappuccino and spire: Two unique maternal-effect loci required for both the anteroposterior and dorsoventral patterns of the Drosophila embryo. Genes \& Dev. 3: 1437-1452.

Marchler-Bauer, A. and Bryant, S.H. 2004. CD-Search: Protein domain annotations on the fly. Nucleic Acids Res. 32: W327-W331.

Martin, J.H., Benzer, S., Rudnicka, M., and Miller, C.A. 1993. Calphotin: A Drosophila photoreceptor cell calcium-binding protein. Proc. Natl. Acad. Sci. 90: 1531-1535.

Misra, S., Crosby, M.A., Mungall, C.J., Matthews, B.B., Campbell, K.S., Hradecky, P., Huang, Y., Kaminker, J.S., Millburn, G.H., Prochnik, S.E., et al. 2002. Annotation of the Drosophila melanogaster euchromatic genome: A systematic review. Genome Biol. 3: RESEARCH0083.

Morse, D.P., Aruscavage, P.J., and Bass, B.L. 2002. RNA hairpins in noncoding regions of human brain and Caenorhabditis elegans mRNA are edited by adenosine deaminases that act on RNA. Proc. Natl. Acad. Sci. 99: 7906-7911.

Palladino, M.J., Keegan, L.P., O'Connell, M.A., and Reenan, R.A. 2000. A-to-I pre-mRNA editing in Drosophila is primarily involved in adult nervous system function and integrity. Cell 102: 437-449.

Palladino, M.J., Bower, J.E., Kreber, R., and Ganetzky, B. 2003. Neural dysfunction and neurodegeneration in Drosophila $\mathrm{Na}^{+} / \mathrm{K}^{+}$ATPase a subunit mutants. J. Neurosci. 23: 1276-1286.

Prasanth, K.V., Prasanth, S.G., Xuan, Z., Hearn, S., Freier, S.M., Bennett, C.F., Zhang, M.Q., and Spector, D.L. 2005. Regulating gene expression through RNA nuclear retention. Cell 123: 249-263.

Quinlan, M.E., Heuser, J.E., Kerkhoff, E., and Mullins, R.D. 2005. Drosophila Spire is an actin nucleation factor. Nature 433: 382-388.

Reinke, R. and Zipursky, S.L. 1988. Cell-cell interaction in the Drosophila retina: The bride of sevenless gene is required in photoreceptor cell R8 for R7 cell development. Cell 55: 321-330.

Rozen, S. and Skaletsky, H. 2000. Primer3 on the WWW for general users and for biologist programmers. Methods Mol. Biol. 132: 365-386.

Rubin, G.M., Hong, L., Brokstein, P., Evans-Holm, M., Frise, E., Stapleton, M., and Harvey, D.A. 2000. A Drosophila complementary DNA resource. Science 287: 2222-2224.

Rueter, S.M., Dawson, T.R., and Emeson, R.B. 1999. Regulation of alternative splicing by RNA editing. Nature 399: 75-80.

Satterfield, T.F., Jackson, S.M., and Pallanck, L.J. 2002. A Drosophila homolog of the polyglutamine disease gene SCA2 is a dosage-sensitive regulator of actin filament formation. Genetics 162: 1687-1702.

Schumacher, M.A., Rivard, A.F., Bachinger, H.P., and Adelman, J.P. 2001. Structure of the gating domain of a $\mathrm{Ca}^{2+}$-activated $\mathrm{K}^{+}$channel complexed with $\mathrm{Ca}^{2+} /$ calmodulin. Nature 410: 1120-1124.

Schumacher, M.A., Crum, M., and Miller, M. 2004. Crystal structure of apocalmodulin and an apocamodulin/SK2 CaMBD complex: Mechanism of $\mathrm{Ca}^{2+}$-activated SK channel grating. Structure 12: 849-860.

Seto, E.S., Bellen, H.J., and Lloyd, T.E. 2002. When cell biology meets development: Endocytic regulation of signaling pathways. Genes \& Dev. 16: 1314-1336.
Spyropoulos, I.C., Liakopoulos, T.D., Bagos, P.G., and Hamodrakas, S.J. 2004. TMRPres2D: High quality visual representation of transmembrane protein models. Bioinformatics 20: 3258-3260.

Stapleton, M., Carlson, J., Brokstein, P., Yu, C., Champe, M., George, R., Guarin, H., Kronmiller, B., Pacleb, J., Park, S., et al. 2002a. A Drosophila full-length cDNA resource. Genome Biol. 3: RESEARCH0080.

Stapleton, M., Liao, G., Brokstein, P., Hong, L., Carninci, P., Shiraki, T., Hayashizaki, Y., Champe, M., Pacleb, J., Wan, K., et al. 2002b. The Drosophila gene collection: Identification of putative full-length cDNAs for $70 \%$ of $D$. melanogaster genes. Genome Res. 12: 1294-1300.

Stolc, V., Gauhar, Z., Mason, C., Halasz, G., van Batenburg, M.F., Rifkin, S.A., Hua, S., Herreman, T., Tongprasit, W., Barbano, P.E., et al. 2004. A gene expression map for the euchromatic genome of Drosophila melanogaster. Science 306: 655-660.

Takai, Y., Sasaki, T., and Matozaki, T. 2001. Small GTP-binding proteins. Physiol. Rev. 81: 153-208.

Thompson, J.D., Gibson, T.J., Plewniak, F., Jeanmougin, F., and Higgins, D.G. 1997. The CLUSTAL_X windows interface: Flexible strategies for multiple sequence alignment aided by quality analysis tools. Nucleic Acids Res. 25: 4876-4882.

Tonkin, L.A., Saccomanno, L., Morse, D.P., Brodigan, T., Krause, M., and Bass, B.L. 2002. RNA editing by ADARs is important for normal behavior in Caenorhabditis elegans. EMBO J. 21: 60256035.

Tupy, J.L., Bailey, A.M., Dailey, G., Evans-Holm, M., Siebel, C.W., Misra, S., Celniker, S.E., and Rubin, G.M. 2005. Identification of putative noncoding polyadenylated transcripts in Drosophila melanogaster. Proc. Natl. Acad. Sci. 102: 5495-5500.

Verstreken, P., Kjaerulff, O., Lloyd, T.E., Atkinson, R., Zhou, Y., Meinertzhagen, I.A., and Bellen, H.J. 2002. Endophilin mutations block clathrin-mediated endocytosis but not neurotransmitter release. Cell 109: 101-112.

Wang, Q., Khillan, J., Gadue, P., and Nishikura, K. 2000. Requirement of the RNA editing deaminase ADAR1 gene for embryonic erythropoiesis. Science 290: 1765-1768.

Webel, R., Haug-Collet, K., Pearson, B., Szerencsei, R.T., Winkfein, R.J., Schnetkamp, P.P., and Colley, N.J. 2002. Potassium-dependent sodium-calcium exchange through the eye of the fly. Ann. N.Y. Acad. Sci. 976: 300-314.

Wellington, A., Emmons, S., James, B., Calley, J., Grover, M., Tolias, P., and Manseau, L. 1999. Spire contains actin binding domains and is related to ascidian posterior end mark-5. Development 126: 5267-5274.

Xia, X.M., Fakler, B., Rivard, A., Wayman, G., Johnson-Pais, T., Keen, J.E., Ishii, T., Hirschberg, B., Bond, C.T., Lutsenko, S., et al. 1998. Mechanism of calcium gating in small-conductance calcium-activated potassium channels. Nature 395: 503-507.

Xia, S., Yang, J., Su, Y., Qian, J., Ma, E., and Haddad, G.G. 2005. Identification of new targets of Drosophila pre-mRNA adenosine deaminase. Physiol. Genomics 20: 195-202.

Yamada, K., Lim, J., Dale, J.M., Chen, H., Shinn, P., Palm, C.J., Southwick, A.M., Wu, H.C., Kim, C., Nguyen, M., et al. 2003. Empirical analysis of transcriptional activity in the Arabidopsis genome. Science 302: 842-846.

Yang, W., Chendrimada, T.P., Wang, Q., Higuchi, M., Seeburg, P.H., Shiekhattar, R., and Nishikura, K. 2006. Modulation of microRNA processing and expression through RNA editing by ADAR deaminases. Nat. Struct. Mol. Biol. 13: 13-21.

Yoshie, S., Imai, A., Nashida, T., and Shimomura, H. 2000. Expression, characterization, and localization of Rab26, a low molecular weight GTP-binding protein, in the rat parotid gland. Histochem. Cell Biol. 113: 259-263. 

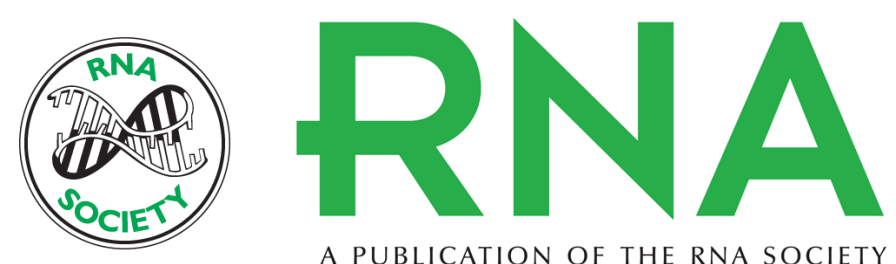

A PUBLICATION OF THE RNA SOCIETY

\section{RNA editing in Drosophila melanogaster: New targets and functional consequences}

Mark Stapleton, Joseph W. Carlson and Susan E. Celniker

RNA 2006 12: 1922-1932 originally published online October 3, 2006

Access the most recent version at doi:10.1261/rna.254306

References This article cites 81 articles, 30 of which can be accessed free at:

http://rnajournal.cshlp.org/content/12/11/1922.full.html\#ref-list-1

License

Email Alerting Receive free email alerts when new articles cite this article - sign up in the box at the Service top right corner of the article or click here. 